\title{
The Retrospective Evaluation of The Local Tumor Control and Adverse Effects of Treatment in Patients Treated Using Cyberknife Stereotactic Radiotherapy in Vestibular Schwannomas
}

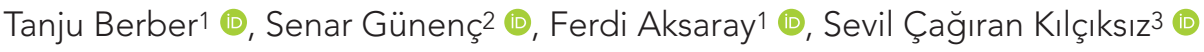 \\ ${ }^{1}$ ìstanbul Okmeydanı Training and Research Hospital, Clinic of Radiation Oncology, İstanbul, Turkey \\ 2University of Health Sciences, Clinic of Radiation Oncology, Van, Turkey \\ ${ }^{3}$ Giresun University Faculty of Medicine, Department of Radiation Oncology, Giresun, Turkey
}

Cite this article as: Berber T, Senar Günenç S. The Retrospective Evaluation of The Local Tumor Control and Adverse Effects of Treatment in Patients Treated Using Cyberknife Stereotactic Radiotherapy in Vestibular Schwannomas. JAREM 2020;10(1): 10-5

\begin{abstract}
Objective: Although the most common tumors of the cerebellopontin angle of the vestibular schwannomas (VS) are benign tumors and are rarely fatal due to their localizations, the symptoms of the disease decreases the quality of life. The aim of the present study was to evaluate the local tumor control, hearing functions, and the adverse effects of treatment of radiotherapy using Cyberknife $₫$ device which is a recently popular non-invasive procedure causing minimum toxicity in the neighboring tissues with sharp dose decreases in the treatment of patients with VS particularly in intracranial tumors.

Methods: Cyberknife $®$ radiosurgery was administered to 28 patients diagnosed with VS in the present study. The patients were followed-up with routine radiologic screening, audiologic tests, and with the evaluation of the neurologic functions. The study was performed retrospectively, and the data of the patients were obtained from the archive files.

Results: CyberKnife $®$ stereotactic radiotherapy was administered to 28 patients diagnosed with VS. The mean follow-up time was 40.25 months. Local control rate was found as $100 \%$ in the follow-ups, the rate of protection of hearing in patients with adequate level of hearing was $73.6 \%$, and the protection rates of the facial and trigeminal nerves was found as $100 \%$. No statistically significant difference was detected in the distribution of the age, treatment dose, and tumor sizes in patients in accordance with the deterioration of hearing after treatment. Conformity index (Cl), and coverage were found as the predictive factors in the protection of hearing.

Conclusion: The investigation of the stereotactic results of VSs in the literature showed that local control and hearing functions were moderately protected, and cranial nerve associated toxicity was found in moderate levels. The treatment parameters of $\mathrm{Cl}$ and coverage were found as the predictive values in the protection of functional hearing after treatment. Randomized controlled prospective studies in patient groups with longer follow-up periods were required for ultimately determining the reliability of this treatment modality.

Keywords: Vestibular schwannoma, CyberKnife $®$, radiosurgery, radiotherapy, stereotaxy
\end{abstract}

\section{INTRODUCTION}

The aim was to evaluate the tumor local control rates, hearing functions, and adverse effects of treatment in patients with clinically or radiologically proven cerebellopontin angle (CPA) tumor [vestibular schwannoma (VS) or meningioma], who were treated using the stereotactic radiosurgery (SRS) or fractionated radiosurgery (FSRT) method in Radiation Oncology CyberKnife ${ }^{\circledR}$ unit in Okmeydanı Training and Research Hospital between July 2012 and October 2014. Patients with tumor size higher than $3 \mathrm{~cm}$ or patients who had a history of previous surgical treatment were excluded from the study.

Approximately $10 \%$ of all intracranial tumors stemmed from the CPA, and VSs constituted the majority of the tumors of this region $(1,2)$. These tumors, previously known as VS, constituted

ORCID IDs of the authors: T.B. 0000-0002-4087-4760; S.G. 0000-0001-8585-9524; F.A. 0000-0002-0107-0735; S.Ç.K. 0000-0001-7947-8338 
than $1 \mathrm{~cm}$, and a total of 18-25 Gy radiation was administered in 3 to 5 fractions for the tumors larger in diameter than $1 \mathrm{~cm}$ (10-12).

The hearing functions of all patients before and after CyberKnife ${ }^{\circledR}$ treatment were evaluated using audiometry. Pure tone threshold audiogram, the average pure tone, speech recognition threshold, and Speech Discrimination score were investigated in pure tone audiometry. Gardner-Robertson class for each patient was identified using the pure tone average, and speech discrimination scores (13). The patient group in class 1 was able to speak on the phone with the affected side. The patient group in class 2 (with pure tone audiogram threshold lower than $50 \mathrm{~dB}$, and speech discrimination score higher than $50 \%$ ) was accepted in the critical threshold for hearing. The hearing levels of patients in class 1 and 2 were evaluated as moderate levels. The hearing levels of patients in class 3 and in poor levels were evaluated as inadequate and/or poor.

Diagnosis of all patients were performed using the radiologic screening. Magnetic resonance imaging (MRI) and computed tomography $(\mathrm{CT})$ were used in radiologic screening. CT and contrast enhanced MRI screening of all patients were performed before the treatment, and tumor size and tumor localization were identified. Post-treatment local tumor control follow-up was performed using the contrast enhanced MRI. The tumor was contoured in each axial section over these images, and tumor diameter and tumor volume were measured.

The $5^{\text {th }}, 7^{\text {th }}$, and $8^{\text {th }}$ nerves were clinically evaluated before and after the treatment. The House \& Brackmann classification was used in the clinical evaluation of the facial nerve function. Trigeminal nerve functions were evaluated as the normal, increased, or decreased sense using a semiquantitative scale. The functions of the other cranial nerves were recorded as temporary and permanent deficit.

The symptoms of all patients before and after the treatment (headache, tinnitus, ataxia, vertigo, etc.) were questioned and recorded to the clinical files. Scoring of headache could not be performed; however, the presence or absence of headache was evaluated. The symptoms were recorded as maintained, disappeared in the routine follow-ups.

\section{Statistical Analysis}

The IBM SPSS Statistics 22 (IBM SPSS, Turkey) program was used in the statistical analysis of the data. The compliance of parameters to normal distribution was evaluated using the Shapiro-Wilks test. Student's t-test was used in the comparison of parameters in normal distribution, and The Mann-Whitney $U$ test was used in the comparison of non-normal distribution between two groups in the quantitative comparison of data, in addition to the descriptive statistical methods (mean, standard deviation, and frequency) in the evaluation of the study data. The paired sample t-test was used in the pretreatment-posttreatment comparisons of the normal distribution parameters, and the Wilcoxon signed test was used in the comparisons of the non-normal distribution parameters. The McNemar test was used in the comparison of was administered for 3 patients who had a tumor diameter smaller 
the qualitative data. Pearson's correlation analysis was used in investigating the association between the parameters in normal distribution, and the Spearman's rho correlation analysis was used in the investigation of the association of parameters in non-normal distribution. The significance was evaluated in $p<0.05$ level.

\section{RESULTS}

The present study was performed with 28 patients diagnosed with VS, who were administered Cyberknife ${ }^{\circledR}$ stereotactic radiotherapy between July 2012 and October 2014.

The patient characteristics, tumor, and treatment parameters are summarized in Table 1. The comparison of the pretreatment tumor diameter and volume and hearing tests with post-treatment values were not statistically significantly different between the mean tumor diameter before the treatment and after the treatment ( $p>0.05)$. There was no statistically significant difference between the tumor volumes before the treatment and after the treatment $(p>0.05)$. No statistically significant difference was detected in tumor diameter and volume in the mean $40.25 \pm 7.68$

\section{Table 1. Patient, tumor, and treatment characteristics}

\begin{tabular}{|c|c|c|}
\hline & $\begin{array}{l}\text { Minimum- } \\
\text { maximum }\end{array}$ & Mean \pm SD \\
\hline Age (year) & $26-71$ & $50.14 \pm 12.71$ \\
\hline \multicolumn{3}{|l|}{$\operatorname{Sex}(n \%)$} \\
\hline Woman & 17 & 60.7 \\
\hline Man & 11 & 39.3 \\
\hline \multicolumn{3}{|l|}{ Age groups ( $n \%$ ) } \\
\hline Below 60 years & 23 & 82.1 \\
\hline 60 years and above & 5 & 17.9 \\
\hline Follow-uptime (month) & $30-54$ & $40.25 \pm 7.68$ \\
\hline $\begin{array}{l}\text { Pre-treatment tumor diameter } \\
(\mathrm{mm})\end{array}$ & $11-29$ & $17.89 \pm 5.65$ \\
\hline $\begin{array}{l}\text { Post-treatment tumor } \\
\text { diameter }(\mathrm{mm})\end{array}$ & $10-28$ & $17.61 \pm 5.45$ \\
\hline Pre-treatment tumor volume & $360-12600$ & $3206.93 \pm 3500.68$ \\
\hline Post-treatment tumor volume & $359-12591$ & $3203.75 \pm 3496.02$ \\
\hline Pre-treatment SSA score & $0-92$ & $40.46 \pm 26.58$ \\
\hline Post-treatment SSA score & $8-92$ & $48.89 \pm 25.81$ \\
\hline $\begin{array}{l}\text { Pre-treatment speech } \\
\text { discrimination score }\end{array}$ & $4-100$ & $59.07 \pm 31.29$ \\
\hline $\begin{array}{l}\text { Post-treatment speech } \\
\text { discrimination score }\end{array}$ & $6-94$ & $54.21 \pm 28.06$ \\
\hline Pre-treatment GR score & $1-5$ & $2.04 \pm 1.07$ \\
\hline Post-treatment GR score & $1-5$ & $2.18 \pm 1.19$ \\
\hline $\mathrm{Cl}$ & $1.18-1.85$ & $1.32 \pm 0.14$ \\
\hline $\mathrm{HI}$ & $1.13-1.55$ & $1.25 \pm 0.08$ \\
\hline Coverage & $95.2-99.9$ & $98.35 \pm 1.16$ \\
\hline Mean cochlear dose & $98-2305$ & $1177.04 \pm 594.42$ \\
\hline
\end{tabular}

(30-54 months) months follow-up after the treatment, and the local control rate was $100 \%$.

The increase in the mean sensorineural audiogram (SSA) score after the treatment was found to be statistically significant compared to the score before the treatment $(p=0.001 ; p<0.01$, respectively). The decrease in the mean speech discrimination score after the treatment was found to be statistically significant compared to the value before the treatment $(p=0.024 ; p<0.05$, respectively). No statistically significant difference was detected in Gardner-Robertson scores before and after the treatment ( $p>0.05)$.

There was a statistically significant association to negative direction between the $\mathrm{Cl}$ and the change differences in SSA scores before and after the treatment in $57.3 \%$ levels ( $r=-0.573$; $p=0.001 ; p<0.01$ ). There was a statistically significant association in positive direction between the coverage values and the change differences of SSA scores before and after the treatment in $59.6 \%$ levels $(r=0.596 ; p=0.001 ; p<0.01)$.

The correlation of the change in speech discrimination in accordance with the tumor size and treatment parameters was statistically significantly associated with positive direction between the $\mathrm{Cl}$ values and the change differences in the speech discrimination scores before and after the treatment in 38\% levels $(r=0.380 ; p=0.046 ; p<0.05)$.

The effects of age and sex on the speech discrimination were demonstrated in Table 2.

The rate of the protection of hearing was found as $73.6 \%$ in the study. Deterioration was detected in hearing functions of 5 patients who had pretreatment functional hearing.

No toxicity associated with facial, trigeminal, and other cranial nerves was detected before and after the treatment. The protection rate of the facial and trigeminal nerve functions was found as $100 \%$ in the present study.

No pseudoprogression was detected in the routine radiological follow-up of the patients in the study.

The decrease in the rate of ataxia after the treatment (3.6\%) was found to be statistically significant compared to the rate of ataxia before the treatment $(25 \%)(p=0.031 ; p<0.05)$. The decrease in the detection rate of headache after the treatment (32.1\%) was found

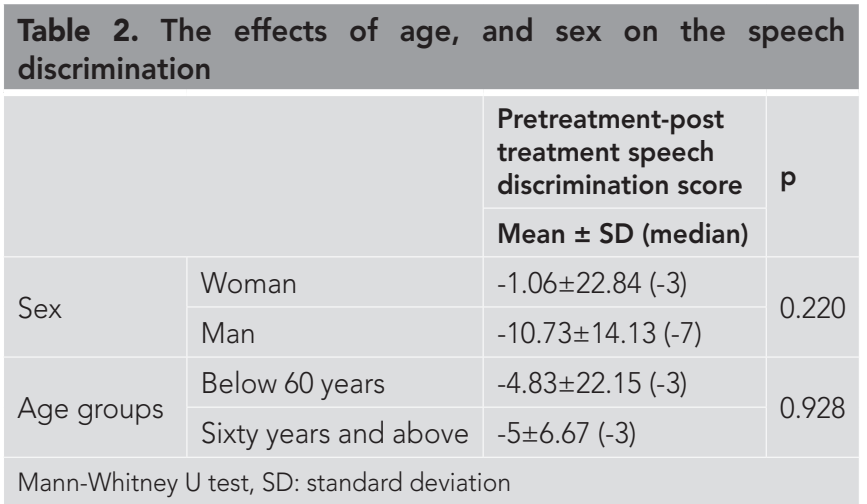


Table 3. A summary of the other studies in the literature and of our study

\begin{tabular}{|c|c|c|c|c|c|c|c|c|}
\hline Author & $\begin{array}{l}\text { No of } \\
\text { patients }\end{array}$ & Dose (Gy) & Fraction & $\begin{array}{l}\text { Local control } \\
\text { rate }(\%)\end{array}$ & $\begin{array}{l}\text { Hearing protection } \\
\text { rate }(\%)\end{array}$ & $\begin{array}{l}\text { Facial nerve } \\
\text { protection rate (\%) }\end{array}$ & $\begin{array}{l}\text { Trigeminal nerve } \\
\text { protection rate (\%) }\end{array}$ & $\begin{array}{l}\text { Follow-up } \\
\text { (month) }\end{array}$ \\
\hline Murphy and Suh (14) & 117 & 13 & 1 & 91 & Unknown & 95 & 99 & 38 \\
\hline Chopra et al. (24) & 216 & 13 & 1 & 92 & 44 & 100 & 95 & 68 \\
\hline Noren (13) & 669 & Unknown & 1 & 95 & $65-70$ & Unknown & Unknown & Unknown \\
\hline Kondziolka et al. (12) & 162 & 16 & 1 & 98 & 51 & 79 & 73 & $60-120$ \\
\hline Maire et al. (32) & 45 & 50.4 & 28 & 86 & 78 & 100 & 100 & 80 \\
\hline Fuss et al. (33) & 51 & 57.6 & 32 & 98 & 85 & 100 & 96 & 42 \\
\hline Shirato et al. $(34)^{2}$ & 65 & 50 & 25 & 92 & Unknown & Unknown & Unknown & 37 \\
\hline Henze et al. (35) & 39 & 54 & Unknown & 95 & Unknown & Unknown & Unknown & 36 \\
\hline Williams al. (38) & 125 & 25 & 5 & 100 & Unknown & 100 & 98 & 22 \\
\hline Chang et al. (16) & 61 & 18 & 3 & 98 & 74 & 100 & 97 & 48 \\
\hline Poen et al. (39) & 31 & 21 & 3 & 97 & 77 & 97 & 84 & 24 \\
\hline Ishihara et al. (40) & 28 & 17 & 3 & 94 & 93 & 100 & 100 & 32 \\
\hline Our study & 28 & $12-25$ & $1-5$ & 100 & 73.6 & 100 & 100 & 40 \\
\hline
\end{tabular}

to be statistically significant compared to the detection rate of headache $(60.7 \%)$ before the treatment $(p=0.021 ; p<0.05)$.

\section{DISCUSSION}

VSs constitute $6-8 \%$ of primary intracranial brain tumors and $60-78 \%$ of CPA tumors (13). The prevalence is 1 in 100.000 (14). In parallel with the developments in radiologic screening, the diagnosis of VS may be accomplished when the tumor size is smaller. The studies which evaluated the treatment in VS were retrospective, and the evidence level of the studies were level 3 or smaller (15). Therefore, there is a lack of evidence-based guide in treatment. The increase of the treatment options in VS and the scarce number of randomized and controlled studies of treatment options led the physicians to interdisciplinary study, and to evaluation in the diagnosis and treatment of the disease. VS is rarely life-threatening, thus the main target in treatment is to provide local tumor control and to protect the moderate hearing and organ functions. The tumor size, age, the general condition of the patient, whether the hearing will be protected, the chance of the protection of the $5^{\text {th }}$ and $7^{\text {th }}$ nerves, tumor growth rate, the presence of neurofibromatosis type 2, the adequate local tumor control, and the treatment associated adverse events are considered in the selection of the treatment. The current treatment approaches are close follow-up, SRS, fractioned radiotherapy, and microsurgery resection. The aim in the CyberKnife ${ }^{\circledR}$ radiosurgery and FSRT treatment techniques is to pause the tumor growth or to minimize the tumor by administrating radiation in a single or several sessions. CyberKnife ${ }^{\circledR}$ functions in the guidance of the real time screening, and rigid immobilization of patient is not required. The comparison of the treatment results of CyberKnife ${ }^{\circledR}$ radiosurgery (steorotactic radiosurgery) and FSRT with surgical treatment showed that similar local control rates were obtained. In addition, this method provides a noninvasive treatment option with the possibility of the better protection of the $5^{\text {th }}$ and $7^{\text {th }}$ cranial nerves (16).

Three patients were administered CyberKnife ${ }^{\circledR}$ radiosurgery at 12 Gy, and 25 patients were administered FSRT between 18 and 25 Gy in the present study. Local control rate was found as $100 \%$. The treatment doses and local control rates in our study were parallel with the doses and local control rates of the other researchers; however, the mean follow-up period was between 5 and 10 years in the studies in the literature, and our mean follow-up time was 40 (40.25 \pm 7.68 months) months. Therefore, the possible progressions in our longer period follow-ups may cause lower local control rates.

Pseudoprogression is generally detected in the first 2 years after radiosurgery. Hathout showed that the pseudoprogression rate was higher in patients who underwent previous surgery before SRS (17). Therefore, treatment should not be regarded unsuccessful before the month 24 of the treatment, and treatment approach should not be changed before the month 36 unless there is a clinical requirement (18). We detected no pseudoprogression in the patients in our study group, which may be explained by that the patients who underwent previous surgery were excluded from the study.

The use of fractioned stereotactic radiotherapy for VSs minimizes the radiation associated damage of the neighboring cranial 
nerves compared to the use of single fraction radiosurgery. The facial and trigeminal toxicity rate was found as $5 \%$ in the 4 - year follow-up of 37 patients who were administered CyberKnife ${ }^{\circledR}$ FSRT (10-12). The facial nerve protection rate was reported as $74-100 \%$, and the trigeminal nerve protection rate was reported as $73-100 \%$ in an analysis which evaluated 17 studies in the literature (19). We detected no toxicity associated with facial and trigeminal nerves in patients who were administered SRS or FSRT in our study. The protection rate of cranial nerves was $100 \%$, which was similar with the results in the literature.

A summary of the other studies in the literature and of our study is presented in Table $3(7,20-23)$. As Cyberknife ${ }^{\circledR}$ is a relatively new device in our country, there are not enough studies on this subject yet.

Our study was similar to the studies in the literature regarding the local control, moderate hearing, and cranial nerves protection rates $(20,24-26)$. There were differences in the studies investigating the predictive factors demonstrating the moderate hearing level after the treatment. No significant association of factors such as age, sex, tumor size, tumor volume, mean cochlear dose, and Homogeneity index was found with the hearing protection in our study (27-29). The moderate $\mathrm{Cl}$ and coverage rates in treatment were found as the predictive values for hearing protection.

\section{CONCLUSION}

The investigation of the stereotactic radiotherapy results of VSs showed that local control was obtained, hearing functions were protected in moderate levels, and cranial nerve-associated toxicity was in moderate levels. CyberKnife ${ }^{\circledR}$ stereotactic radiotherapy is a good treatment option in VS patients particularly with tumor diameter smaller than $3 \mathrm{~cm}$. Randomized controlled prospective studies in patient groups with longer follow-up period are required for the ultimate identification of the reliability of this treatment modality and for preparing a guideline.

Ethics Committee Approval: Ethics committee approval was received for this study from the Ethics Committe of Okmeydanı Training and Research Hospital (approval number: 267, date: 03.02.2015).

Informed Consent: This is a retrospective study. Patient data were taken from the files.

Peer-review: Internally peer-reviewed.

Author Contributions: Surgical and Medical Practices - T.B.; Concept - T.B.; Design - T.B.; Data Collection and/or Processing - T.B.; Analysis and/ or Interpretation - T.B., S.G.; Literature Search - T.B., S.G.; Writing Manuscript - T.B.

Conflict of Interest: The authors have no conflict of interest to declare.

Financial Disclosure: The authors declared that this study has received no financial support.

\section{REFERENCES}

1. Roberti F, Sekhar LN, Kalavakonda C, Wright DC. Posterior fossa meningiomas: Surgical experience in 161 cases. Surg Neurol 2001; 56: 8-20.

2. Propp JM, McCarthyn BJ, Davis FG, Preston-Martin S. Descriptive epidemiology of vestibular schwannomas. Neurol Clin 2006; 8: 1-11.

3. Haines DE, Frederickson RG: The meninges. In Al Mefty $\mathrm{O}$ (ed), Meningiomas. New York: Raven Pres, 1991: 9-10.
4. Gardner G, Robertson JH. Hearing preservation in unilateral acoustic neuroma surgery. Ann Otol Rhinol Laryngol 1988; 97: 55-66.

5. Pulec JL. Acoustic neuroma surgery in geriatric patients. Ear Nose Throat J 1999; 78: 429-40.

6. Carlson ML, Jacob JT, Pollock BE, Neff BA, Tombers NM, Driscoll CL, et al. Long-term hearing outcomes following stereotactic radiosurgery for vestibular schwannoma: patterns of hearing loss and variables influencing audiometric decline. J Neurosurg 2013; 118: 579-87.

7. Kondziolka D, Flickinger JC, Lunsford LD. The principles of skull base radiosurgery. Neurosurg Focus 2008; 24: E11.

8. Çağıran SK, Turna M, Adatepe F, Çelik SE. Vestibular Schwannoma'da Stereotaktik Radyocerrahi: Olgu Sunumu. Okmeydanı Tıp Dergisi 2013; 29: 14-6.

9. Hasegawa T, Kida Y, Kato T, lizuka H, Kuramitsu S, Yamamoto T. Long term safety and efficacy of stereotactic radiosurgery for vestibular schwannomas: evaluation of 440 patients more than 10 years after treatment with Gamma Knife surgery. J Neurosurg 2013; 118: 557-65.

10. Sakamoto GT, Sinclair J, Gibbs IC, et al. Stereotactic Radiosurgery for Acoustic Neuromas Using the CyberKnife®. In: Mould RF (eds). Library of Congress Cataloging-in-Publication Data, Robotic Radiosurgery, Volume

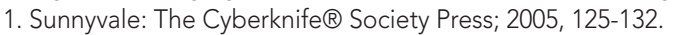

11. Arthurs BJ, Fairbanks RK, Demakas JJ, Lamoreaux WT, Giddings NA, Mackay AR, et al. A review of treatment modalities for vestibular schwannoma. Neurosurg Rev 2011; 34: 265-77.

12. Kondziolka D, Lunsford LD, McLaughlin MR, Flickinger JC. Long-term outcomes after radiosurgery for acoustic neuromas. N Eng J Med 1998; 339: 1426-33.

13. Noren G. Gamma knife radiosurgery of acoustic neurinomas. A historic perspective. Neurochirurgie 2004; 50: 253-6.

14. Murphy ES, Suh JH. Radiotherapy for vestibular schwannomas: a critical review. Int J Radiat Oncol Biol Phys 2011; 79: 985-97.

15. Combs SE, Thilmann C, Debus J, Schulz-Ertner D. Long-term outcome of stereotactic radiosurgery (SRS) in patients with acoustic neuromas. Int J Radiat Oncol Biol Phys 2006; 64: 1341-7.

16. Chang SD, Gibbs IC, Sakamoto GT, Lee E, Oyelese A, Adler JR Jr. Staged stereotactic irradiation for acoustic neuroma. Neurosurgery 2005; 56: 1254-61.

17. Karam SD, Tai A, Strohl A, Steehler MK, Rashid A, Gagnon G, et al. Frameless fractionated stereotactic radiosurgery for vestibular schwannomas: a single-institution experience. Front Oncol 2013; 3: 121.

18. Combs SE, Welzel T, Schulz-Ertner D, Huber PE, Debus J, Differences in clinical results after INAC-based single dose radiosurgery versus fractionated stereotactic radiosurgery. Int J Radiat Oncol Biol Phys 2010; 76: $193-200$

19. Morimoto M, Yoshioka Y, Kotsuma T, Adachi K, Shiomi H, Suzuki O, et al. Hypofractionated Stereotactic Radiation Therapy in Three to Five Fractions for Vestibular Schwannoma. Jpn J Clin Oncol 2013; 43: 805-12.

20. Hathout L, Lambert C, Carrier JF, Bahary JP, Hervieux Y, Moumdjian RA, et al. Transient Tumor Volume Increase in Vestibular Schwannomas after Radiotherapy. 2012.

21. Hayhurst $\mathrm{C}$, Zadeh $\mathrm{G}$. Tumor pseudoprogression following radiosurgery for vestibular schwannoma. Neuro Oncol 2012; 14: 87-92.

22. Kano H, Kondziolka D, Khan A, Flickinger JC, Lunsford LD. Predictors of hearing preservation after stereotactic radiosurgery for acoustic neuroma. J Neurosurg 2009; 111: 863-73.

23. Pollock BE, Driscoll CL, Foote RL, Link MJ, Gorman DA, Bauch CD, et al. Patient outcomes after vestibular schwannoma management: prospective comparison of microsurgical resection and stereotactic radiosurgery. Neurosurgery 2006; 59: 77-85.

24. ChopraR, Kondziolka D, Niranjan A, Lunsford LD, Flickinger JC. Longterm follow-up of acoustic schwannoma radiosurgery with marginal tumor doses of 12 to 13 Gy. Int J Radiat Oncol Biol Phys 2007; 68: 845-51.

25. Meijer OW, Vandertop WP, Baayen JC, Slotman BJ. Single-fraction vs. fractionated linac-based stereotactic radiosurgery for vestibular schwannoma: A single-institution study. Int J Radiat Oncol Biol Phys 2003; 56: 1390-6. 
26. Massager N, Nissim O, Delbrouck C, Delpierre I, Devriendt D, Desmedt $F$, et al. Irradiation of cochlear structures during vestibular schwannoma radiosurgery and associated hearing outcome. J Neurosurg 2007; 107: 733-9.

27. Bhandare N, Jackson A, Eisbruch A, Pan CC, Flickinger JC, Antonelli P, et al. Radiation therapy and hearing loss. Int J Radiat Oncol Biol Phys 2010; 76(3 Suppl): 50-7.

28. Thomas C, Di Maio S, Ma R, Vollans E, Chu C, Clark B, et al. Hearing preservation following fractionated stereotactic radiotherapy for vestibular schwannomas: Prognostic implications of cochlear dose. J Neurosurg 2007; 107: 917-26.

29. Tsao MN, Sahgal A, Xu W, De Salles A, Hayashi M, Levivier M, et al. Steorotactic radiosurgery for vestibular schwannoma: International Stereotactic Radiosurgery Society (ISRS) Practice Guideline. J Radiosurg SBRT 2017; 5: 5-24.

30. Iwai $Y$, Yamanaka K, Kubo T, Aiba T. Gamma knife radiosurgery for intracanalicular acoustic neuromas. J Clin Neurosci 2008; 15: 993-7.

31. Szumacher E, Schwartz ML, Tsao M, Jaywant S, Franssen E, Wong CS. Fractionated stereotactic radiotherapy for the treatment of vestibular schwannomas: combined experience of the Toronto-Sunnybrook Regional Cancer Centre and the Princess Margaret Hospital. Int J Radiat Oncol Biol Phys 2002; 53: 987-91.

32. Maire J-P, Huchet A, Milbeo Y, Darrouzet V, Causse N, Célérier D. Twenty years' experience in the treatment of acoustic neuromas with fractionated radiotherapy: a review of 45 cases. Int J Radiat Oncol Biol Phys 2006; 66: 170-8.

33. Fuss $M$, Debus J, Lohr $F$, Huber $P$, Rhein B, Engenhart-Cabillic R. Conventionally fractionated stereotactic radiotherapy (FSRT) for acoustic neuromas. Int J Radiat Oncol Biol Phys 2000; 48: 1381-7.
34. Shirato H, Sakamoto T, Takeichi N, Aoyama H, Suzuki K, Kagei K. Fractionated stereotactic radiotherapy for vestibular schwannoma (VS): comparison between cystic-type and solid-type VS. Int J Radiat Oncol Biol Phys 2000; 48: 1395-401.

35. Henzel M, Hamm K, Sitter H, Gross MW, Surber G, Kleinert G. Comparison of stereotactic radiosurgery and fractionated stereotactic radiotherapy of acoustic neurinomas according to 3-D tumor volume shrinkage and quality of life. Strahlenther Onkol 2009; 185: 567-73.

36. Kapoor S, Batra S, Carson K, Shuck J, Kharkar S, Gandhi R. Longterm outcomes of vestibular schwannomas treated with fractionated stereotactic radiotherapy: an institutional experience. Int J Radiat Oncol Biol Phys 2011; 81: 647-53.

37. Sakanaka K, Mizowaki T, Arakawa Y, Araki N, Oya N, Takahashi JA. Hypofractionated stereotactic radiotherapy for acoustic neuromas: safety and effectiveness over 8 years of experience. Int J Clin Oncol 2011; 16: 27-32.

38. Williams J. Fractionated radiotherapy for acoustic neuromas. Congress of Neurological Surgeons: 50th Annual Meeting 2000. San Antonio, TX: 155

39. Poen JC, Golby AJ, Forster KM, Martin DP, Chinn DM, Hancock SL. Fractionated stereotactic radiosurgery and preservation of hearing in patients with vestibular schwannoma: a preliminary report. Neurosurgery 1999; 45: 1299-307.

40. Ishihara H, Saito K, Nishizaki T, Kajiwara K, Nomura S, Yoshikawa K, et al. CyberKnife radiosurgery for vestibular schwannoma. min-Minimally Invasive Neurosurgery 2004; 47: 290-3. 